\title{
Effect Relationships among Coaching Leadership, Job Satisfaction, Trust, and Organizational Loyalty
}

\author{
Sun-Hwa Kim11), Won-seok Bang2), Kuk-Hoan Wee3)
}

\begin{abstract}
Recently, the effectiveness of coaching has attracted attention from the practical field as well as from academia. Coaching skill focuses on growth and achievement that not only meets the needs of the members of the organization, but also empowers them. This study consists of four sub-factors as the main elements of coaching behavior based on previous research, as the behavioral factors of coaching leadership, by identifying the relationship between coaching leadership and job satisfaction, trust and oganizational loyalty. I would like to reveal the effectiveness of coaching leadership. To this end, a questionnaire survey was conducted for members working at the Lifelong Education Center, and for verification, an AMOS 21.0 program was used to conduct confirmatory factor analysis and structural equation path analysis As a result of the study, first, it was found that coaching leadership had a positive and significant effect on trust and job satisfaction. Second, the direct effect of coaching leadership on organizational loyalty was dismissed. In other words, it was found that trust and job satisfaction parameters have an indirect effect on organizational loyalty, but no direct effect. Finally, the effect of trust and job satisfaction on organizational loyalty was found to have a significant positive effect. Therefore, it is important that not only lifelong education institutions, but also organizational leaders must increase the trust and job satisfaction of members through the exercise of coaching leadership. The results of this study give theoretical and practical implications.
\end{abstract}

Keywords: Coaching Leadership, Trust, Job Satisfaction, Organizational Loyalty

\section{Introduction}

Leaders are responsible for creating and communicating the culture of the organization, which is delivered to followers who deliver the organization's culture and values[1]. Coaching leadership is a new and effective leadership style that affects the organization's attitude,

Received(March 26, 2020), Review Result(1st: April 24, 2020, 2nd: June 13, 2020), Accepted(June 25, 2020)

1) (Student, First Author) 48434 Dept. Education, Kyungsung University, Daeyeon 3(sam)-dong, Nam-gu, Busan, Korea email: yama6161@naver.com

2) (Professor, Co Author) 52725 Dept. Business, Gyeongnam Science and Technology Univ., Chiram-dong, Jinju-si, Gyeongsangnam-do, Korea

email: bangws@daum.net

3) (Student, Corresponding Author) 48513 Dept. Industry, Pukyong National Univ., Daeyeon 3(sam)-dong, Nam-gu, Busan Korea email: wkh64@pusan.ac.kr 
behavior, and organizational performance[2].

In recent years, the effectiveness of coaching has attracted a lot of attention from the practical field as well as from academia, as coaching skills focus on growth and achievement that not only meet the needs of the members of the organization, but also empower them. Coaching, which can open the minds of employees to working with new ideas and other approaches, enables talent-based management to improve the growth and performance of not only members, but also of the entire organization, which, in turn, contributes to achieving the goals[3]. Further, coaching is a key to enabling success in creating organizational performance and is recognized as a key competency in organizational leadership[4].

Meanwhile, leaders play an important role in developing their employees' competence by developing their own ability to perform their own tasks through coaching. The coaching of leaders is very popular in the area of human resource development and is used as a tool for organizational development.

Previous research to improve the status of coaching is also continuously increasing. For this reason, many studies on coaching in the field of business have attempted to identify the competency of coaching and the influence of coaching. Although coaching has been introduced in Korea over 20 years ago, and despite some relevant research on the importance of coaching and the positive effects of coaching utilization, the studies related to the performance or effectiveness of coaching are scarce[5].

Given the effectiveness of coaching leadership, the present study aims to provide academic and practical implications through identifying the relationship between coaching leadership and related variables.

\section{Literature Review}

\subsection{Creating Shared Value (CSV)}

Kunst et al. (2018) showed that one-on-one interaction between leaders and employees in the workplace provides leaders with specific environmental cues to influence their potential goal orientation, as well as to guide and inspire employee performance improvement[6]. Several relevant studies have demonstrated that coaching for organizational members of leaders is a necessary element to develop employees' potential competencies and improve work performance[7].

For instance, Park, Ju-Hyeon (2016) proposed that coaching is a process that provides 
direction through dialogue as a positive influence to change the behavior or attitude of members[8]. He presented the four sub-dimensions of coaching: direction presentation, accountability, development and relationship.

The present study focuses on four sub-factors suggested as the main elements of coaching behavior. We examine the effect relationships among coaching leadership, job satisfaction, trust, and organizational loyalty. By doing so, we intend to investigate the effectiveness of coaching leadership.

Based on a review of previous studies, the following hypothesis was formulated:

Hypothesis 1: Coaching leadership would have a positive impact on organizational loyalty.

\subsection{Job Satisfaction}

Kalkavan and Katrinli (2014) demonstrated the relationships among manager coaching on employee performance, job satisfaction, role ambiguity, and manager satisfaction[9]. According to their results, the coaching of managers has a positive effect not only on job satisfaction of employees, but also on organizational commitment and job performance. Based on these findings, the following hypothesis was formulated:

Hypothesis 2: Coaching leadership would have a positive impact on job satisfaction.

\subsection{Trust}

Trust refers to the degree of belief that other parties will act as expected[10]. The foundation for trust in people is motivated and guided by optimistic and positive intentions for the welfare and interests of colleagues. Accordingly, members of an organization have faith in their manager's trustworthy behavior and show a psychological motivation to follow the leader at the risk, even if they have some disadvantages. Therefore, coaching behavior of a leader, presenting directness for the correct job through coaching leadership, with a favorable relationship through open communication with employees, and employees' competency development, will increase the trust of employees to leader.

Based on the above, the following hypothesis was formulated:

Hypothesis 3: Coaching leadership would have a positive impact on trust. 


\subsection{Organizational Loyalty}

Organizational loyalty is "a state in which employees want to remain in the organization and have an interest in and attachment to the organization and have positive emotions while committing to the organization"[11].

Recent research has suggested that employee trust has a positive effect on employee satisfaction and is related to the attitude and behavioral loyalty through commitment[12]. Therefore, based on the previous studies, the following two hypotheses were formulated:

Hypothesis 4: Job satisfaction would have a positive impact on organizational loyalty. Hypothesis 5: Trust would have a positive Impact on organizational loyalty.

\section{Research Model and Method}

\subsection{Research Model}

This paper aims to identify the effect relationships among coaching leadership, trust, job satisfaction and organizational loyalty. The conceptual model for the effect relationship between coaching leadership and the related variables is shown in [Fig. 1].

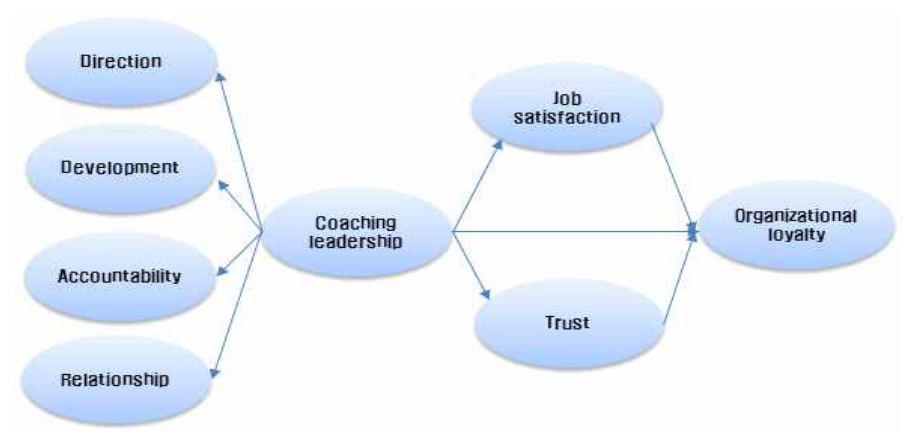

[Fig. 1] Research Model

\subsection{Method}

To achieve the purpose of this study, a questionnaire was distributed to employees of Lifelong Education Centers in Gyeongnam and Busan. The survey was conducted from October 15 to October 25, 2019. A total of 253 of the questionnaire were collected; upon the removal of unfaithful answers, 241 copies were used for further statistical analysis. Using the statistical program AMOS 21.0, confirmatory factor analysis was performed for reliability and validity 
testing, and path analysis was performed for hypothesis testing.

\subsection{Operational Definition of Variables}

\subsubsection{Coaching Leadership}

In the present study, coaching leadership was deemed to consist of four factors: direction, development, accountability, and relationship. The measurement items were adapted from Ladegard and Gjerde (2014) and Park, Ju-Hyeon (2016). A 5-point Likert scale was used (1 = strongly disagree, 5 = strongly agree).

\subsubsection{Job Satisfaction}

Job satisfaction is defined as satisfaction with the passion for work, reward, etc. as the overall satisfaction of the job that the organization members feel. The measurement items were adapted from [13] and measured on a 5 -point Likert scale $(1=$ strongly disagree, $5=$ strongly agree).

\subsubsection{Trust}

Trust is composed of four items-namely, trust in organizational leaders, understanding and caring for members, and treating them fairly. The scales were adapted from the previous studies, such as Ladegard and Gjerde (2014). The scales were appropriately modified for the purpose of this study and measured on a 5 -point Likert scale $(1=$ strongly disagree, $5=$ strongly agree).

\subsubsection{Organizational Loyalty}

In this study, the operational definition of organizational loyalty is that the employees' enthusiasm and internal motivation to demonstrate emotional commitment to and dedication to the organization are manifested as actions. The items for measuring organizational loyalty were partially modified from Park, Bo-Ram (2015)[14]. The construct consisted of 4 items such as pride, word of mouth, recommendation of others, and so forth.

\section{Results}

\subsection{Confirmatory Factor Analysis}

The model was evaluated through the fitness index using a maximum likelihood. In order to 
confirm the overall model fit by conducting confirmatory factor analysis, the items that did not meet the criteria such as factor loading were deleted. The loading factor of each item, except for the deleted item, was found to be 0.6 or higher, so that the scales of each constituent concept constituting the measurement model were considered to have concentration and discriminant validity[15].(Woo Jong-pil, 2012). The goodness of fit was $\mathrm{x} 2$ / df $=779.447$ (278), $\mathrm{p}=0.000, \mathrm{CMIN} / \mathrm{DF}=2.804, \mathrm{IFI}=.929, \mathrm{TLI}=.909, \mathrm{CFI}=.928, \mathrm{RMSEA}=0.087$, os the model was judged to be generally suitable. In addition, the Cronbach's a value of each variable was 0.874 or higher, the conceptual reliability value was 0.872 or higher, and the variance extraction index (AVE) value was 0.696 or higher. [Table 1] reports the results of analyzing the overall reliability and validity.

[Table 1] Results of Confirmatory Factor Analysis

\begin{tabular}{|c|c|c|c|c|c|c|c|}
\hline Variables & Items & Estimates & SE & T-value & Cronbach'a & $\mathrm{CR}$ & AVE \\
\hline \multirow{4}{*}{ Directness } & $\mathrm{X} 1$ & 0.853 & 0.050 & 19.182 & \multirow{4}{*}{0.923} & \multirow{4}{*}{0.924} & \multirow{4}{*}{0.752} \\
\hline & $\mathrm{X} 2$ & 0.815 & 0.049 & 17.430 & & & \\
\hline & $\mathrm{X} 3$ & 0.897 & 0.048 & 21.581 & & & \\
\hline & $X 4$ & 0.901 & - & - & & & \\
\hline \multirow{4}{*}{ Development } & $X 5$ & 0.887 & 0.045 & 19.926 & \multirow{4}{*}{0.940} & \multirow{4}{*}{0.941} & \multirow{4}{*}{0.799} \\
\hline & $\mathrm{X6}$ & 0.917 & 0.047 & 20.874 & & & \\
\hline & X7 & 0.895 & 0.050 & 22.081 & & & \\
\hline & $\mathrm{X} 8$ & 0.877 & - & - & & & \\
\hline \multirow{3}{*}{ Accountability } & X9 & 0.823 & 0.054 & 16.975 & \multirow{3}{*}{0.899} & \multirow{3}{*}{0.890} & \multirow{3}{*}{0.729} \\
\hline & $\mathrm{X} 10$ & 0.869 & 0.053 & 18.815 & & & \\
\hline & $\mathrm{X} 12$ & 0.869 & - & - & & & \\
\hline \multirow{4}{*}{ Relationship } & $\mathrm{X} 13$ & 0.892 & - & - & \multirow{4}{*}{0.924} & \multirow{4}{*}{0.924} & \multirow{4}{*}{0.753} \\
\hline & $\mathrm{X} 14$ & 0.865 & 0.036 & 22.447 & & & \\
\hline & $\mathrm{X} 15$ & 0.841 & 0.031 & 22.736 & & & \\
\hline & $\mathrm{X} 16$ & 0.873 & 0.038 & 18.700 & & & \\
\hline \multirow{4}{*}{$\begin{array}{c}\text { Job } \\
\text { Satisfaction }\end{array}$} & $\mathrm{X} 17$ & 0.752 & 0.042 & 22.447 & \multirow{4}{*}{0.929} & \multirow{4}{*}{0.934} & \multirow{4}{*}{0.780} \\
\hline & $\mathrm{X} 18$ & 0.910 & 0.044 & 22.736 & & & \\
\hline & $\mathrm{X} 20$ & 0.951 & 0.049 & 18.700 & & & \\
\hline & $\mathrm{X} 21$ & 0.907 & - & - & & & \\
\hline \multirow{4}{*}{ Trust } & $\mathrm{X} 22$ & 0.903 & - & - & \multirow{4}{*}{0.937} & \multirow{4}{*}{0.938} & \multirow{4}{*}{0.792} \\
\hline & $\mathrm{X} 23$ & 0.908 & 0.057 & 17.634 & & & \\
\hline & X25 & 0.837 & 0.054 & 19.957 & & & \\
\hline & $\mathrm{X} 26$ & 0.909 & 0.053 & 18.746 & & & \\
\hline \multirow{3}{*}{$\begin{array}{c}\text { Organizational } \\
\text { Loyalty }\end{array}$} & $\mathrm{X} 27$ & 0.892 & - & - & \multirow{3}{*}{0.874} & \multirow{3}{*}{0.872} & \multirow{3}{*}{0.696} \\
\hline & $\mathrm{X} 28$ & 0.832 & 0.055 & 16.447 & & & \\
\hline & X29 & 0.774 & 0.061 & 14.655 & & & \\
\hline
\end{tabular}




\subsection{Correlation Analysis}

To test the level of discriminant validity among potential variables, the correlations between the potential variables and the magnitude of the variance extraction index (AVE) were compared. As a result of testing discriminant validity, all the squared correlation coefficients among potential variables were lower than the AVE value, and discriminant validity was sufficiently secured. [Table 2] shows the results of the correlation analysis.

[Table 2] Results of Correlation Analysis

\begin{tabular}{|c|c|c|c|c|c|c|c|}
\hline & V1 & $\mathrm{V} 2$ & $\mathrm{~V} 3$ & $\mathrm{~V} 4$ & $\mathrm{~V} 5$ & V6 & V7 \\
\hline $\begin{array}{l}\text { Directness } \\
\text { (V1) }\end{array}$ & 0.906 & & & & & & \\
\hline $\begin{array}{l}\text { Development } \\
\text { (V2) }\end{array}$ & $0.208^{* *}$ & 0.926 & & & & & \\
\hline $\begin{array}{l}\text { Accountability } \\
\text { (V3) }\end{array}$ & $0.174^{*}$ & $0.258^{* *}$ & 0.911 & & & & \\
\hline $\begin{array}{l}\text { Relationship } \\
\text { (V4) }\end{array}$ & $0.086^{* *}$ & $0.226^{* *}$ & $0.164^{* *}$ & 0.958 & & & \\
\hline $\begin{array}{l}\text { Job Satisfaction } \\
\text { (V5) }\end{array}$ & 0.123 & 0.113 & 0.098 & $0.527^{* *}$ & 0.883 & & \\
\hline $\begin{array}{l}\text { Trust } \\
\text { (V6) }\end{array}$ & 0.110 & $0.188^{* *}$ & $0.208^{* *}$ & $0.349^{* *}$ & $0.249^{* *}$ & 0.889 & \\
\hline $\begin{array}{l}\text { Organizational } \\
\text { Loyalty (V7) }\end{array}$ & $0.133^{* *}$ & $0.222^{* *}$ & 0.113 & 0.074 & 0.075 & $0.140^{*}$ & 0.834 \\
\hline \multicolumn{8}{|c|}{$\begin{array}{l}\text { Note: Note: Diagonal elements are each construct's AVE squared (in bold) } \\
\text { Significant value at }{ }^{*} \mathrm{p}=0.05,{ }^{* *} \mathrm{p}=0.01,{ }^{* * *} \mathrm{p}=0.001\end{array}$} \\
\hline
\end{tabular}

\subsection{Path Analysis}

[Table 3] indicates a result of conducting a path analysis to test the hypothesis of the relationships among coaching leadership, job satisfaction, trust, and organizational loyalty. As a result of examining a goodness-of-fit index of the path model, $\mathrm{x} 2 / \mathrm{df}=832.851(290)$, and the goodness-of-fit model was found to be generally suitable, because the CMIN / DF value was 2.872, and the RMSEA value was 0.088, which meets the reference value. In addition, the IFI and CFI values, which are the incremental conformity index, were 0.926 and 0.922 , respectively, and the TLI values were 0.904, which satisfied the standard. As a result of the path analysis, all hypotheses except $\mathrm{H} 3$ and 4 were supported.

Specifically, the results were as follows. First, regarding H1, the coaching leadership of the 
leader had a positive and significant effect on the job satisfaction (Path coefficient: 0.877, p < 0.001). Second, the results for $\mathrm{H} 2$, coaching leadership was found to be positively linked to trust (Path coefficient: 0.954, $\mathrm{p}<0.001$ ). This means that coaching leadership of leader improved the trust. Third, H3 according to which coaching leadership would improve organizational loyalty was rejected. Said differently, coaching leadership was found to have no direct effect on the organizational loyalty of members (Path coefficient: $-0.015, p=0.9$ ). Fourth, $\mathrm{H} 4$ that trust would have a positive effect on organizational loyalty was rejected (Path coefficient: $0.071, \mathrm{p}=0.6$ ). Finally, as to the results for H5, job satisfaction was found to have a positive effect on organizational loyalty (Path coefficient: 0.774, $\mathrm{p}<0.001$ ).

[Table 3] Results of Path Analysis

\begin{tabular}{c|c|c|c|c|c|c}
\hline $\begin{array}{c}\text { Hypo-t } \\
\text { hesis }\end{array}$ & Path & $\begin{array}{c}\text { Estim-a } \\
\text { tes }\end{array}$ & SE & T-value & p-value & Results \\
\hline H1 & $\begin{array}{c}\text { Coaching leadership } \\
\rightarrow \text { Jog satisfaction }\end{array}$ & 0.877 & 0.061 & $14.401^{* * *}$ & $* * *$ & Supported \\
\hline H2 & $\begin{array}{c}\text { Coaching leadership } \\
\rightarrow \text { Trust }\end{array}$ & 0.954 & 0.061 & $15.583^{* * *}$ & $* * *$ & Supported \\
\hline H3 & $\begin{array}{c}\text { Coaching leadership } \\
\rightarrow \text { Organizational loyalty }\end{array}$ & -0.015 & 0.175 & -0.086 & 0.931 & Supported \\
\hline H4 & $\begin{array}{c}\text { Trust } \\
\text { Organizational loyalty }\end{array}$ & 0.071 & 0.143 & 0.494 & 0.621 & Supported \\
\hline H5 & $\begin{array}{c}\text { Jog satisfaction } \rightarrow \\
\text { Organizational loyalty }\end{array}$ & 0.774 & 0.092 & $8.373^{* * *}$ & $* * *$ & Supported \\
\hline \multicolumn{2}{c|}{ 2 $/ \mathrm{df}=832.851(290), \mathrm{p}=0.000, \mathrm{CMIN} / \mathrm{DF}=2.872, \mathrm{IFI}=0.926$ TLI=0.904, CFI=0.922, RMSEA=0.088 } \\
\hline
\end{tabular}

Note: Significant value at ${ }^{* *} \mathrm{p}=0.05,{ }^{* * *} \mathrm{p}=0.001$

\section{Conclusions}

Coaching is a new leadership skill that can enhance individual competencies and organizational performance. Due to the effectiveness of coaching, it is gaining attention not only in the practical field, but also in academia. In our empirical study, we demonstrated the effects of director's coaching leadership on organizational loyalty through the job satisfaction and trust of members for lifelong education institutions.

Based on the results of the study, the theoretical and practical implications of this study are as follows. First, it was found that coaching leadership of the director of a lifelong education institution enhances job satisfaction of members. This result is consistent with previous 
studies[16]. That is, as a leader of the organization, the director plays a key role in improving job performance for organizational members. Further, it is thought that coaching leadership of director improves employee satisfaction by setting clear goals, presenting directness, realizing the potential of organizational members, and helping them to develop and demonstrate their capabilities.

Second, the coaching leadership of the director was found to increase the trust of members for the director. Therefore, exerting leadership of the director through coaching behavior of the leader can create positive relations based on trust with the organization members.

Third, in this study, the effect of coaching leadership on organizational loyalty was not supported. Although coaching leadership did not have a direct effect on organizational loyalty, it was found to have an indirect effect through trust and member satisfaction. Therefore, in the present study, it is important for the director to improve the trust and job satisfaction of members through coaching leadership.

A discussed previously, coaching to play an important role in the professional development of the classroom and educational system and in the creation of a learning culture[17]. In addition, coaching is the main style of co-management and collaboration, and it develops and enhances organizational competencies and potential members of the organization.

Accordingly, the results of the present study provide practical important implications. The coaching leadership of organizational leaders not only improves the potential capabilities and professional abilities of organizational members, but also promotes satisfaction and trust by forming a positive and harmonious relationship between leaders and members. In summary, coaching leadership is an effective leadership style to improve loyalty. Accordingly, organization leaders should make an effort to exert the desirable coaching leadership.

\section{Reference}

[1] Lopez, Y. P., Dohrn, S., Posig, M., The effect of abusive leadership by coaches on Division I student-athletes' performance: The moderating role of core self-evaluations, Sport Management Review, (2019), Vol.23, No.1, pp.130-141. DOI:https://doi.org/10.1016/j.smr.2019.07.001

[2] Ladegard, G., Gjerde, S., Leadership coaching, leader role-efficacy, and trust in subordinates, A mixed methods study assessing leadership coaching as a leadership development tool, The Leadership Quarterly, (2014), Vol.25, No.4, pp.631-646.

[3] Kim Su-Jong, The Relationship between Coaching Leadership and Organizational Effectiveness: Focusing on Mediating Effects of Individuality, Relatedness and Job Autonomy, Korea University of Technology \& 
Education, Doctorial Dissertation, (2015)

[4] Boyce, L. A., Jeffrey Jackson, R., Neal, L. J., Building successful leadership coaching relationships: Examining impact of matching criteria in a leadership coaching program, Journal of Management Development, (2010), Vol.29, No.10, pp.914-931.

[5] Kim Eun-Hee, The Influence Leader's Coaching Competency on the Organizational Commitment of the Members, Dongshin University, Doctoral Dissertation, (2015)

[6] Kunst, E. M., van Woerkom, M. van Kollenburg, G. H., Poell, R. F., Stability and change in teachers' goal orientation profiles over time: Managerial coaching behavior as a predictor of profile change, Journal of Vocational Behavior, (2018), Vol.104, February, pp.115-127. DOI: https://doi.org/10.1016/j.jvb.2017.10.003

[7] Song, Yong-Gwan, Cheon, Sung-Hyeon, Chang, Youn-Jeong, Kim, Bo-Ram, The Effects of Controlling Coaching Behavior on Athletes' Psychological Need Satisfaction, Moral Decision-Making and Burnout in Sport Context, Korean Society For The Study of Physical Education, (2016), Vol.21, No.1, pp.69-88.

[8] Park, Ju-Hyeon, A Study on the Effect of Coaching Leadership on the Organizational Commitment: Mediating Effect of Organizational Trust, Seoul Venture University, Doctorial Dissertation, (2016)

[9] Kalkavan, S., Katrinli, A., The effects of managerial coaching behaviors on the employees' perception of job satisfaction, organizational commitment, and job performance: Case study on insurance industry in Turkey, Procedia-Social and Behavioral Sciences, (2014), Vol.150, pp.1137-1147.

[10] Lien, C., Wen, M., Huang, L., Wu, K., Online hotel booking: the effects of brand image, price, trust and value on purchase intentional, Asia Pacific Management Review, (2015), Vol.20, No.4, pp.210-218.

[11] Lee, Hoong-Ki, A Study on the Influence of Confidence on Organization Commitment and Royalty Focused on Employes of Smal \& Midle-Sized Companies around Seoul Metropolitan Area, The Korean Leadership Review, (2013), Vol.4, No.2, pp.71-86.

[12] Yao, T., Qiu, Q., \& Wei, Y., Retaining hotel employees as internal customers: Effect of organizational commitment on attitudinal and behavioral loyalty of employees, International Journal of Hospitality Management, (2019), No.76, Part A, pp.1-8.

[13] Park, Bo-Ram, The Effects of Psychological Capital on Hotel Employees' Job Satisfaction, Organizational Commitment, and Organizational Citizenship Behavior, Youngsan University, Doctorial Dissertation, (2015)

[14] Cho, Peter-Sungkyu, Study on the Infuence of a Five-Star Hotel General Manager's Communiction Style on Employee Job Satisfaction, Dongshin University, Doctoral Dissertation, (2016)

[15] Woo Jong-Pil, The Concept and Understanding of Structural Equation Model, Korea Seoul: Hannarae Publisher, (2012)

[16] Yoon, S. U., Influence that Coaching leadership of Dental Hygienist (Dental practitioners) affects in the Motivational self-concept, Job Satisfaction, Quality of lift, Journal of Digital Convergence, (2018), Vol.16, No.2, pp.261-267.

[17] Devine, M., Meyers, R., Houssemand, C., How can coaching make a positive impact within educational settings?, Procedia-Social and Behavioral Sciences, (2013), Vol,93, pp.1382-1389. 